\title{
Preparation and Characterizations of NiS/ZnS Bilayer Thinfilm by Chemical Bath Deposition Method
}

\author{
J.Yuvaloshinia and Ra.Shanmugavadivub* \\ a Department of Physics, Sree Sevugan Annamalai College, Devakottai, India. \\ bDepartment of Physics, Rajadoraisingam Govt. Arts College, Sivagangai, India. \\ (* corresponding author Email: yuvaloshini $15 @$ gmail.com)
}

\begin{abstract}
NiS/ZnS thin films were grown by Chemical Bath Deposition (CBD) technique using eqimolar aqueous solutions of zinc chloride, nickel chloride and thiourea as precursor. Silicon glass substrates were placed in glass bottles with polypropylene autoclave screw caps containing the precursors described above, and the bath temperature is maintained at $95^{\circ} \mathrm{C}$. X-ray diffraction 28/8 scans showed that the only crystallographic phase present was the hexagonal wurtzite structure. Scanning electron microscopy showed the formation of nanostructures, consisting of hexagonal structures of a few hundred nanometers. The photoluminescence spectra of NiS/ZnS bilayer were recorded at 18-295 K using a cw He-Cd laser $(325 \mathrm{~nm})$ and pulsed laser $(266 \mathrm{~nm})$. The NiS/ZnS nanostructure exhibit an ultraviolet emission band centered at ,:..:; $3.87 \mathrm{eV}$ in the vicinity of the band edge, which is attributed to the well-known excitonic transition in $\mathrm{ZnS}$. The optical properties such as refractive index, electrical and optical conductivities were determined by using UV- VIS absorption spectrometry. The band gap energy was determined as $1.45 \mathrm{eV}$.
\end{abstract}

Keywords: NiS, ZnS, Bilayer, X-ray diffraction (XRD), Scanning Electron Microscope (SEM), Optical property, Photoluminescence

\section{INTRODUCTION}

Alternating lattice-matched perovskite bilayer or ultrathinfilms have been investigated extensively in the search for new functionalities and behavior related to a broad range of materials properties [1]. During the last decade, the thin films of $\mathrm{ZnS}$ and $\mathrm{NiS}$ have received more attention due to their potential applications in various fields of science and technology. Metal chalcogenide films have been widely studied, because of their effective applications in electronic, optical, solar cell, photoconductor and superconductor device [2]. Two important 
factors that should be considered in producing these materials are the band gap energy matching solar spectrum and the competitiveness of production cost. Devices based on this new concept are being realized both in the area of very fast circuits and in optoelectronics. This whole domain, however, is still in its infancy and promises a great deal for the future [3]. They have attracted growing attention over the past twenty years. The technological interest is due to their unique transport properties along the growth direction.

In this report we stated that the synthesis of $\mathrm{NiS} / \mathrm{ZnS}$ bilayer thin films using a simple, reproducible, and cost effective technique called Chemical Bath Deposition [4], ZnS thin films deposited from Zinc chloride containing baths were observed to have average optical absorption for both below and above band gap energies. Therefore for this research work we selected zinc chloride as Zinc source. NiS thin films belong to group VII - VI compound semiconductor materials and have diverse applications in the areas of optoelectronics and electro-optic devices. [5-9].

\section{EXPERIMENTAL DETAILS}

NiS/ZnS bilayer thin films were prepared by Chemical Bath Deposition (CBD) method using (IM) of aqueous solution nickel chloride and (0.2M) of sodium thiosulphate as first precursor. The microscopic glass slides were washed with chromic acid followed by acetone and finally with double distilled water, was placed in beakers containing the precursor described above. The $\mathrm{pH}$ of 1.5 is maintained throughout the experiment with the aid of adding hydrochloric acid $(\mathrm{HCl})$. Triethylamine (TEA) was added as a chelating agent. The time allowed for deposition is $\mathrm{I} h$ at $95^{\circ} \mathrm{C}$. After the deposition, the film was cleaned with distilled water for several times and dried finally. After the deposition of single layer film was achieved, NiS/ZnS bilayer was fabricated by dipping the substrate into a bath containing the second precursor. The second precursor containing IM of zinc chloride, $0.2 \mathrm{M}$ of thiourea and $\mathrm{pH}$ of $\mathrm{I} \mathrm{I}$ is maintained throughout the experiment by means of adding ammonia (Merck $30 \%)$. EDTA was added as a chelating agent. The deposition time and the cleaning process were the same procedure as mentioned above. The as deposited thin films were kept in a furnace and annealed at $400^{\circ} \mathrm{C}$ and $500{ }^{\circ} \mathrm{C}$ for about an hour.

The surface morphology of the NiS/ZnS nanostructures was examined by scanmng electron microscopy (SEM), while their crystal structure was determined by X-ray diffraction (XRD) using a Rigaku diffractometer with CuKa X-rays. The measurements were carried out using a $\mathrm{He}-\mathrm{Cd} \mathrm{cw}$ laser at $325 \mathrm{~nm}$ with full power $35 \mathrm{~mW}$, and a $266 \mathrm{~nm}$ frequency quadrupled solid state-pumped YAG laser with $0.5 \mathrm{~ns}$ pulse width, $7.6 \mathrm{kHz}$ repetition rate 
and $5 \mathrm{~mW}$ average power in order to excite the photoluminescence of the samples. The spectra were recorded using a very sensitive LN2 cooled CCD camera and a UV-visible spectrometer.

\section{RESULTS AND DISSCUSSION}

An obvious change in the XRD peak intensity of NiS/ZnS bilayer thin films is observed with increasing annealing temperature which is shown in FIG 1. From this result, NiS/ZnS films annealed at $400^{\circ} \mathrm{C}$ exhibited a dominant peak at $28=27.92^{\circ}(\mathrm{H})$ and $31.24^{\circ}(\mathrm{H})$ and annealed at $500^{\circ} \mathrm{C}$ films exhibited a high intense dominant peak at $28=31.767^{\circ}(\mathrm{H})$ and other peaks at $19.96^{\circ}(\mathrm{H}), 52.81^{\circ}(\mathrm{R}), 66.276^{\circ}(\mathrm{H})$ which has both the Hexagonal, Rhombohedra Wurtzite phase which is compared with the JCPDS card no(75-0612 and 89-2351). In the present study the grain size of as-deposited and films was estimated from XRD peaks using Debye Scherer formula [10] and was found to be in the range of $40 \mathrm{~nm}-50 \mathrm{~nm}$. No data on the dependence of grain size on annealing temperature of NiS/ZnS films is available in the literature for comparison.

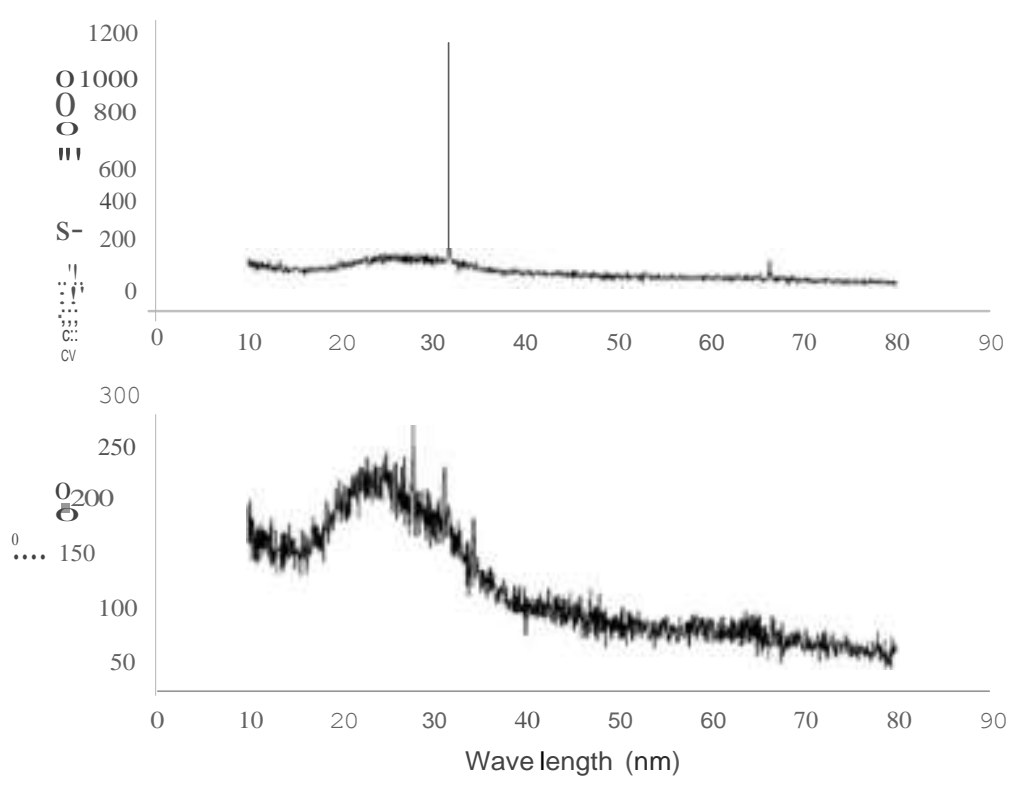

FIG 1. XRD pattern of NiS/ ZnS bilayer annealed at $400^{\circ} \mathrm{C}$ and $500{ }^{\circ} \mathrm{C}$

FIG 2 shows a set of SEM images of the as grown NiS/ZnS bilayer thin films prepared assemblies at different magnifications. The structure was found to be compact and covered the surface of the substrate completely with micro holes, with the grain particles exhibiting granular morphology of the film annealed at $400^{\circ} \mathrm{C}$. FIG 2 (b) shows the SEM 
micrographs of $\mathrm{NiS} / \mathrm{ZnS}$ bilayer thin films annealed at $500^{\circ} \mathrm{C}$ and it is observed as hexagonal structure. Chemical compositions of the constituents' in the coatings, obtained from EDAX spectra for the NiS/ZnS bilayer thinfilm annealed at $400^{\circ} \mathrm{C}$ and $500^{\circ} \mathrm{C}$ are shown in FIG 3 (a) and 3 (b). The other elements $\mathrm{Ca}, \mathrm{Al}, \mathrm{Mg}$ and $\mathrm{Si}$ that are not expected to be in the deposited films may be resulted from the glass substrates [10].
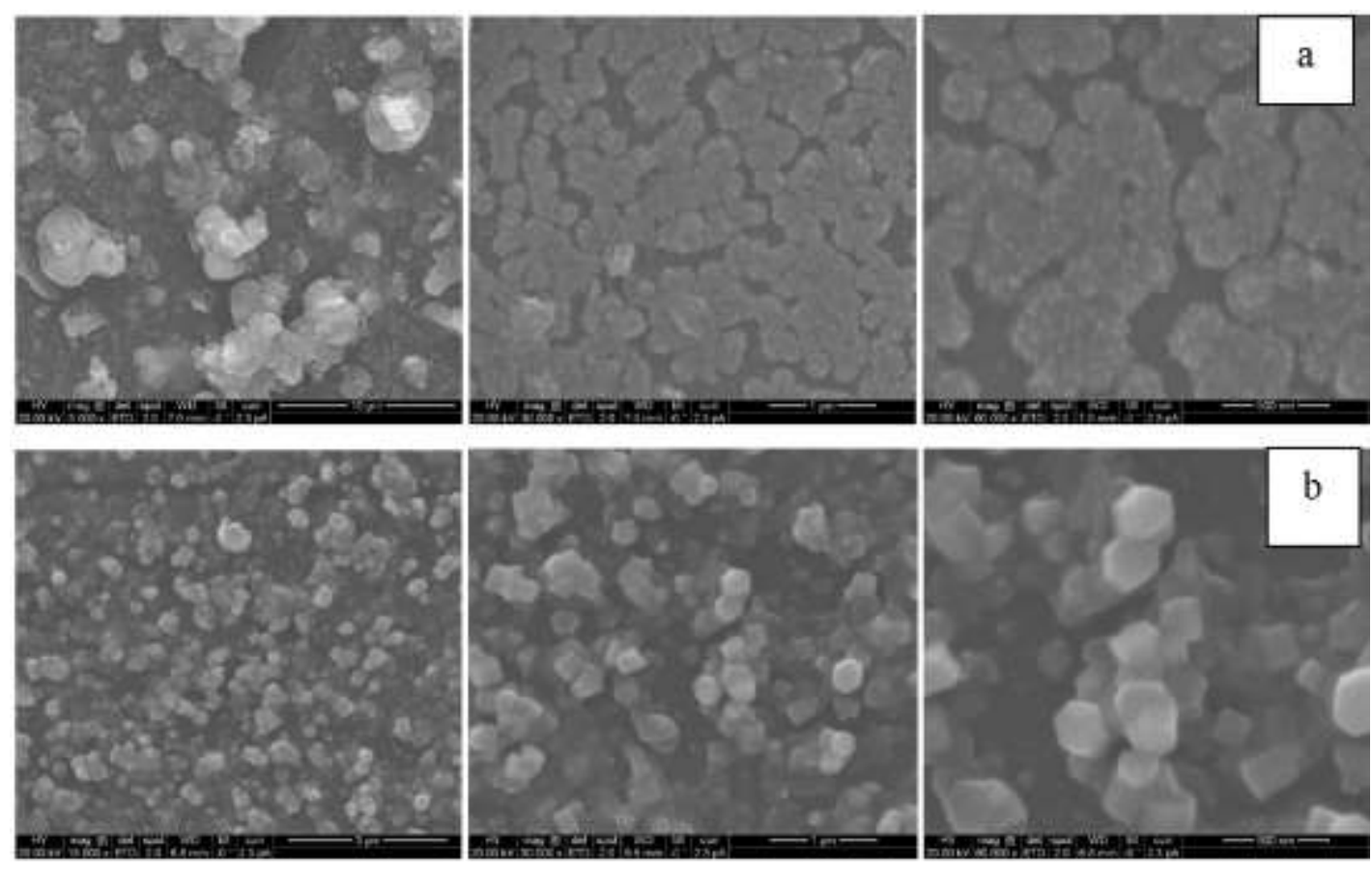

FIG 2. (a) to (b) SEM image of NiS/ $\mathrm{ZnS}$ bilayer annealed at $400^{\circ} \mathrm{C}$ and $500^{\circ} \mathrm{C}$
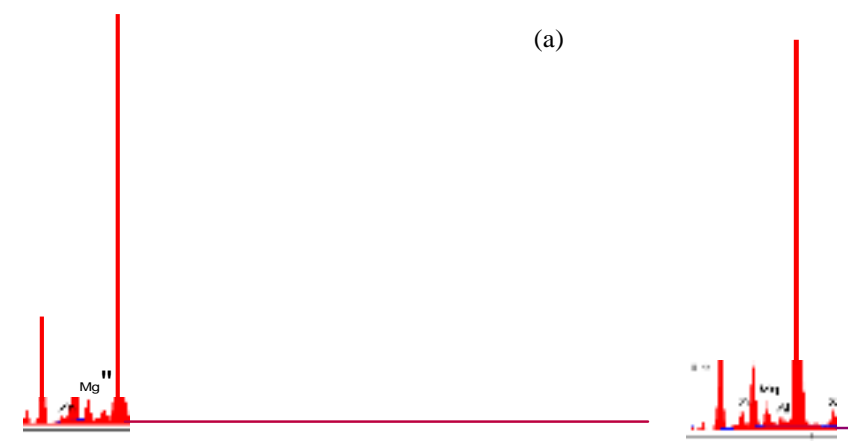

(b)

FIG 3 (a), (b) EDAX images of NiS/ ZnS bilayer annealed at $400^{\circ} \mathrm{C}$ and $500{ }^{\circ} \mathrm{C}$ 
The optical properties of NiS/ZnS bilayer were determined from absorption measurement in the range $300 \mathrm{~nm}$ to $1000 \mathrm{~nm}$. From the spectra, it is observed that, the absorption is higher below $300 \mathrm{~nm}$ and lower in the range of $400 \mathrm{~nm}$ to $900 \mathrm{~nm}$.

The optical transmission spectrum of the NiS/ZnS bilayer thinfilms annealed at $400^{\circ} \mathrm{C}$ and $500^{\circ} \mathrm{C}$ shows good transmission (>60) for wavelengths larger than $500 \mathrm{~nm}$ FIG 4, which is one of the prerequisites' for opto-electronics devices, especially for solar cell window layers. The band gap energy (Eg) and the parameters such as refractive-index (n), dielectric constant (£), optical conductivity ( $\left.\mathrm{cr}_{0}\right)$ and electrical conductivity (cre) were determined by various equations based on UV- absorption spectrum.

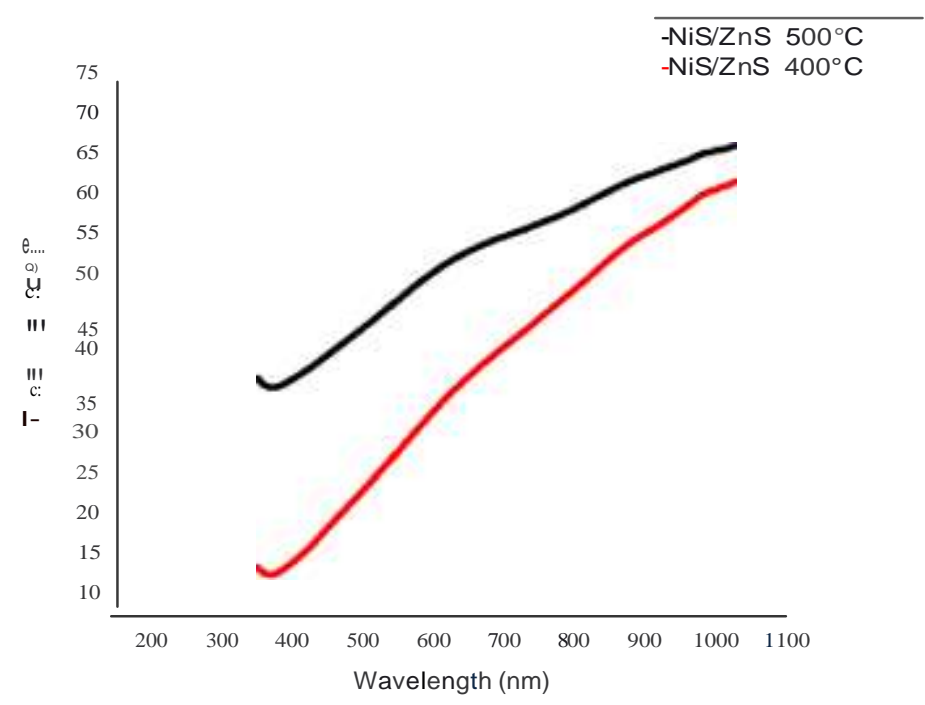

FIG 4 Plot of Transmittance \% Versus Wavelength for NiS/ZnS bilayer annealed at $400{ }^{\circ} \mathrm{C}$ and $500{ }^{\circ} \mathrm{C}$

Absorption coefficient a associated with the strong absorption region of the film was calculated from transmittance $(\mathrm{T})$ using the relation,

Absorption coefficient $a=\stackrel{\operatorname{in}\left(\_!\right)}{--\{-}=\stackrel{1}{\{-}=\ln (;::) \times 10^{6} \mathrm{~m}^{-1}[11]$

The band gap was determined from the intersection of straight portion of $a^{2}$ versus $\mathrm{eV}$ graph which is shown in FIG 5 for NiS/ZnS bilayer thin film. The observed band gap value of the thin films annealed at $400{ }^{\circ} \mathrm{C}$ and $500{ }^{\circ} \mathrm{C}$ are $\mathrm{leV}$ and $1.45 \mathrm{eV}$ respectively. 


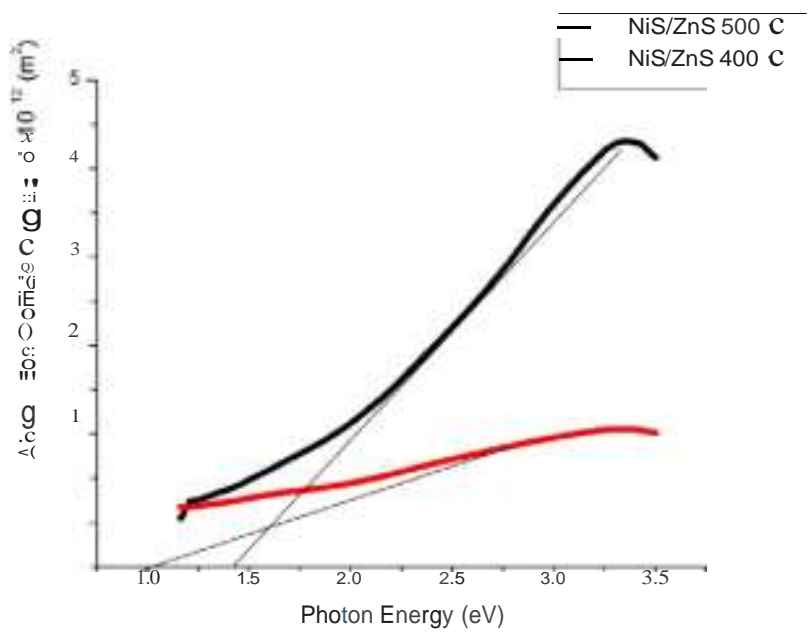

FIG 5 Plot of square of absorption Coefficient $\mathrm{a}^{2}$ Versus Photon energy for NiS/ZnS bilayer annealed at $400{ }^{\circ} \mathrm{C}$ and $500{ }^{\circ} \mathrm{C}$

The coefficient of absorption a is also related to extinction coefficient $\mathrm{K}$ by, Extinction coefficient $\mathrm{K}=\underset{47 \mathrm{~T}}{\text { ail }} \quad[12]$

FIG 6 potrays a plot of extinction coefficient versus photon energy. The extinction coeficient for $\mathrm{NiS} / \mathrm{ZnS}$, is observed that there is a gradual increase from $\mathrm{leV}$ to $3 \mathrm{eV}$ and found a sudden decrease from $3 \mathrm{eV}$ to $5 \mathrm{eV}$.

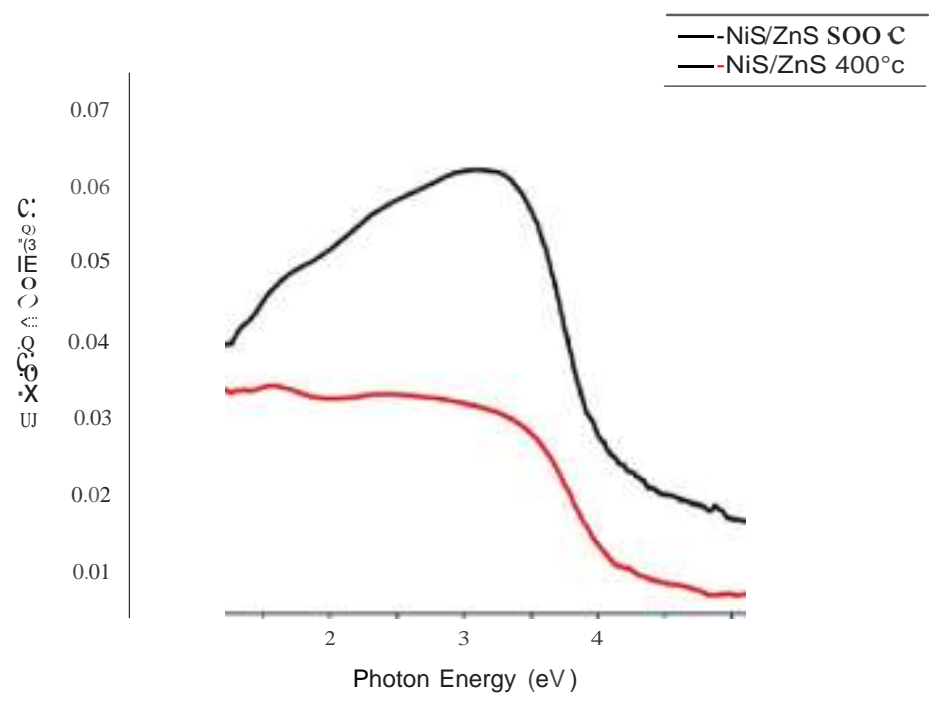

FIG 6 Plot of Extinction Coefficient Versus Photon energy for NiS/ZnS bilayer annealed at $400^{\circ} \mathrm{C}$ and $500^{\circ} \mathrm{C}$ 
The refractive index of film 1s calculated using Modified envelope method [13]. Refractive index

$$
\begin{aligned}
& n=\left[N+\left(N^{2}-n_{0}^{2} n 1^{2}\right) 2^{1}\right.
\end{aligned}
$$

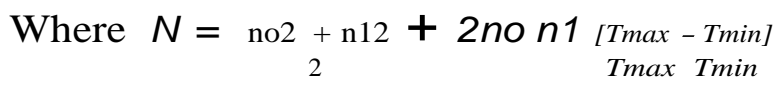

$n_{0}$ is the refractive index of air, $n_{l}$ is the refractive index of the substrate, Tmax and $T_{\min }$ are the maximun and minimum transmittances respectively for a particular wavelength.

The variation of refractive index (n) with wavelength for the as depositied thin films is shown in FIG 7. The high refractive index of 0.7 to 0.1 for wavelength range $200 \mathrm{~nm}$ to $400 \mathrm{~nm}$ and increases to 0.8 for values wavelength range $390 \mathrm{~nm}$ to $1000 \mathrm{~nm}$, which shows variation in the refractive index values. The bilayer of NiS/ZnS with the values of low refractive index which could be useful in applications of antireflection coatings. [14].

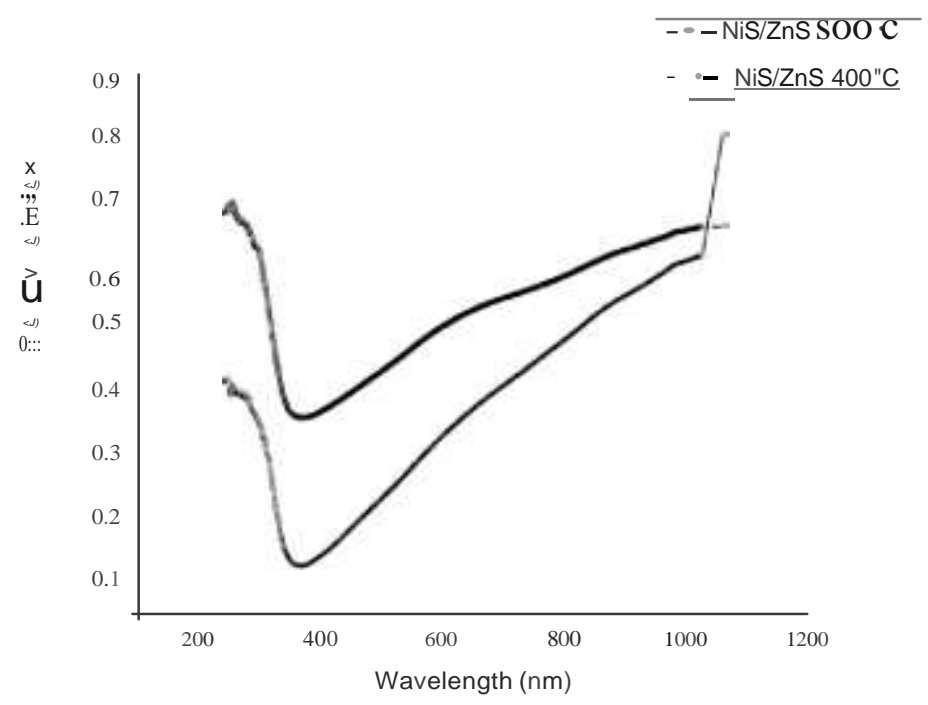

FIG 7 Plot of Refractive Index Versus Wavelength for NiS/ZnS bilayer annealed at $400{ }^{\circ} \mathrm{C}$ and $500{ }^{\circ} \mathrm{C}$

The optical conductivity is given by

Optical conductivity $c_{\delta}=\underset{47 \mathrm{~T}}{a n c}$, where c is the velocity of light in vacuum.

The electrical conductivity Cie is given by the expression [15] 
Electrical conductivity $(\mathrm{Je}=$ znuo

The complex dielectric constant

$$
\varepsilon_{r}-\varepsilon_{r}+\varepsilon_{0},
$$

where $E r=n^{2}-K^{2}$, Eo=ZnK $[16,17]$

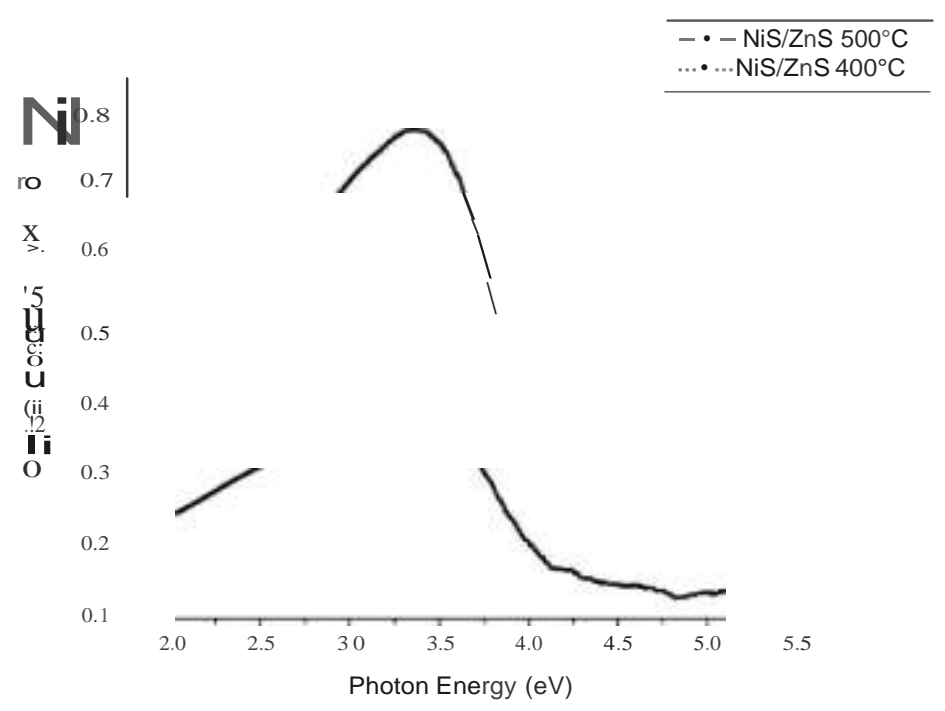

FIG 8 Plot of Optical Conductivity Versus Photon energy for NiS/ZnS bilayer annealed at $400{ }^{\circ} \mathrm{C}$ and $500^{\circ} \mathrm{C}$

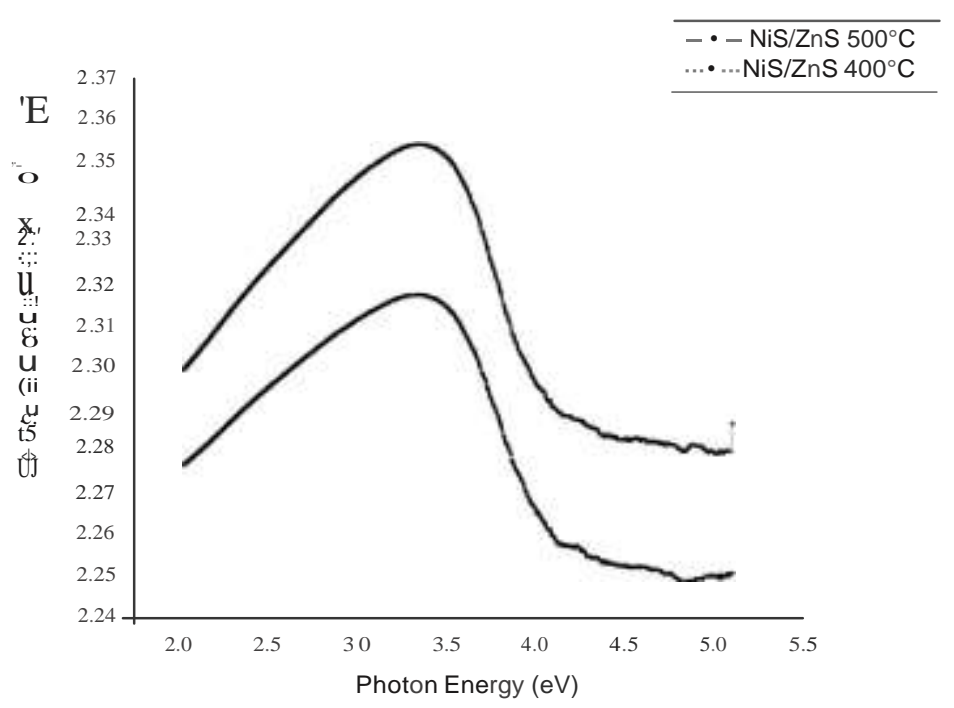

FIG 9 Plot of Electrical Conductivity Versus Photon energy for NiS/ZnS bilayer annealed at $400{ }^{\circ} \mathrm{C}$ and $500{ }^{\circ} \mathrm{C}$ 


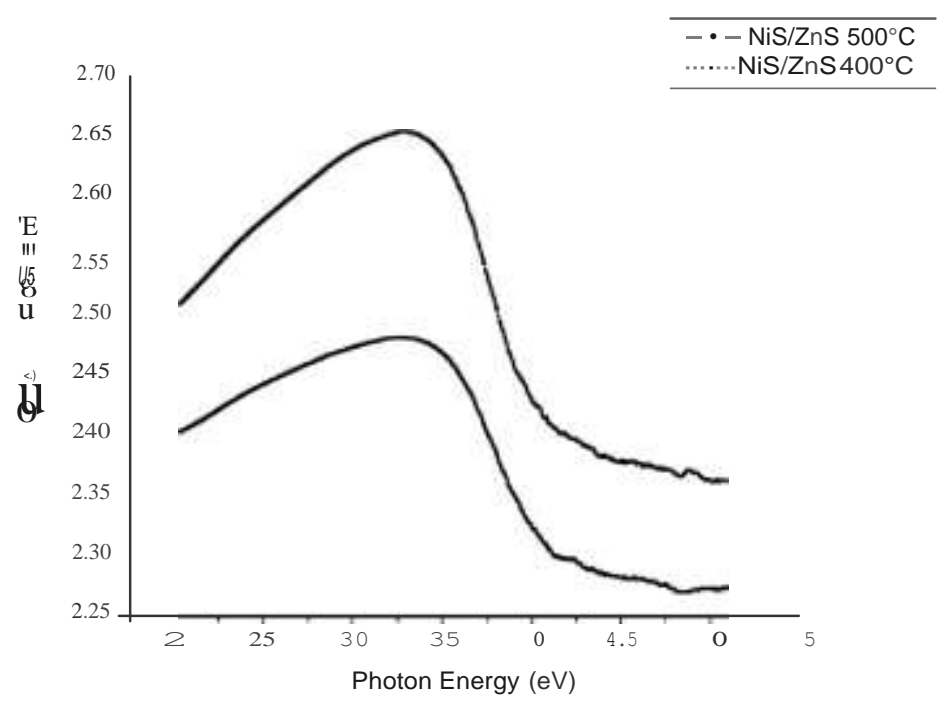

FIG 10 Plot of Dielectric constant Versus Photon energy for NiS/ZnS bilayer annealed at $400{ }^{\circ} \mathrm{C}$ and $500^{\circ} \mathrm{C}$

The optical conductivity cro against photon energy, electrical conductivity Cie against photon energy and dielectric constant versus photon energy for NiS/ZnS are shown in FIG 8,9 and 10 respectively. The nature of the curve of optical, electrical conductivity and dielectric constant has a gradual increase upto $3.5 \mathrm{eV}$ and a sudden decrease from $3.5 \mathrm{eV}$ to $5.0 \mathrm{eV}$ and the observed values are tabulated in Table $\mathrm{I}$.

\begin{tabular}{|c|c|c|c|c|c|c}
\hline \multirow{2}{*}{ NiS/ZnS } & \multicolumn{2}{|c|}{ At $2.00(\mathrm{eV})$} & \multicolumn{2}{c|}{ At $3.50(\mathrm{eV})$} & \multicolumn{2}{c}{ At $5.00(\mathrm{eV})$} \\
\hline $\begin{array}{c}\text { Optical Conductivity } \\
\left(\text { croxl0 }{ }^{13} \mathrm{~s}^{1}{ }^{1}\right)\end{array}$ & $400{ }^{\circ} \mathrm{C}$ & $500{ }^{\circ} \mathrm{C}$ & $400{ }^{\circ} \mathrm{C}$ & $500{ }^{\circ} \mathrm{C}$ & $400{ }^{\circ} \mathrm{C}$ & $500{ }^{\circ} \mathrm{C}$ \\
\cline { 2 - 7 } & 0.25 & 0.4 & 0.35 & 0.8 & 0.1 & 0.3 \\
\hline $\begin{array}{c}\text { Electrical Conductivity } \\
\left(\text { cre } \times 10{ }^{7} \mathrm{~s} / \mathrm{m}\right)\end{array}$ & 2.27 & 2.30 & 2.30 & 2.36 & 2.25 & 2.29 \\
\hline Dielectic constant (Ee) & 2.40 & 2.51 & 2.45 & 2.65 & 2.25 & 2.40 \\
\hline
\end{tabular}

TABLE 1 Optical conductivity, Electrical conductivity and Dielectric constant of the Samples

Photoluminescence (PL) spectra of NiS/ZnS bilayer thin films excited with a $320 \mathrm{~nm}$ Xe lamp source at room temperature are presented in FIG 11. A dominant emission peak centred at $3.75 \mathrm{eV}(330 \mathrm{~nm})$ and $3.87 \mathrm{eV}(320 \mathrm{~nm})$ respectively. This shows strong ultraviolet (UV) 
peak is attributed to the recombination of free excitons through exciton-exciton collision process [18]. The strongest peak is comparatively broad and gives near blue emission bands. The intensity of photoluminescence decreases significantly with increasing temperature.

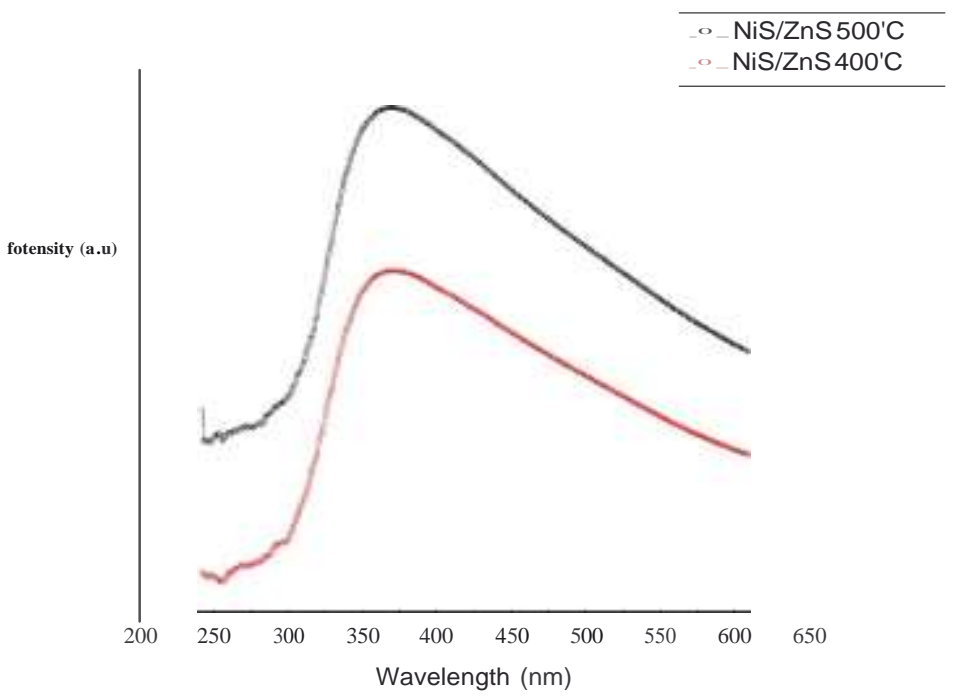

FIG 11 Photoluminescence spectra of NiS/ ZnS bilayer annealed at $400^{\circ} \mathrm{C}$ and $500{ }^{\circ} \mathrm{C}$

\section{CONCLUSION}

NiS/ZnS bilayer thinfilms were sucessfully depositied on glass substrates by CBD technique. The as depositied films posses the wurtzite hexagonal structure and show very good crystalline quality. The atomic composition is confirmed by EDAX spetrum. The photoluminenscences spectra of NiS/ZnS bilayer thin films exhibit a strong UV excitonic peak The band gap energy of bilayer thinfilms were found to be $l e V$ and $1.45 \mathrm{eV}$ respectively. 


\section{References}

[1] R.J.Cava et al., Phys. Rev. Lett., 58 (1987) 523.

[2] B.Asenio, AM.Chaparro, M.T.Gutierrez, J.Herroro, Thin solid Films, 511 (2006) 117120.

[3] L.Esaki and R.Tsu, IBM J. Res. Dev. 14 (1970) 61.

[4] F. Lianghuan, L. Jun, Z. Xinmin, and C. Yaping, Super. \& Microstr., 13 (1992) 87.

[5] S. Ilican, Y. Caglar and M.Caglar, Physica Macedonica , 56, 43, (2006).

[6] S. El-Sayed, Chalcogenide Letters, 6, 241, (2009).

[7] F. S. Al-Hazmi, Chalcogenide Letters, 6, 63, (2009).

[8] A Adam, M. Bahishti, A Majeed Khan, S. Kumar, M. Hussian and M. Zulfequar, Chalcogenide letters, 4, 155, (2007).

[9] Kojihayashi, D. Kato and K. Shimakawa, J.Non-Cryst.Solids 198, 696 (1996)

[10] A Cortes, H. Gomez, RE. Marotti, G. Riveros, E.A. Dalchiele, Sol.Energy Mater. Sol. Cells 82 (2004) 21.

[11] F.Abeles(ed.), Optical properties of solids North Hooland pub. Co., Amsterdam, (1972).

[12] J.I.Pankove, Optical processes in semiconductors, Prentice Hall, New York. (1971).

[13] R.Swanepoel, J.phys.E 16, (1983) 1214.

[14] C.J.Brinker, and M.S.Harrington, Solar Energy Materials 52, (1982) 159.

[15] B.A.Ezeokoye, C.E.Okeke,Nig.Jour.of Solar energy 14, (2003) 82.

[16] R. L. Webber, K. V. Muning, M. W. White, and G. A Weygand, College Physics (McGraw-Hill Book Company Inc., USA) (1974).

[17] F.Wooten, Optical properties of solid Academic press, New York, (1972).

[18] S. C Liu, Y. Zhang, H. Ruh, J- J. Lee, H-W. Shim, E-K. Suh and C. J Lee, Chem. Phys. Lett. 363, 134. 